\title{
Could glutaric acid (GA) replace glutaraldehyde in the preparation of biocompatible biopolymers with high mechanical and thermal properties?
}

\author{
TAPAS MITRA, G SAILAKSHMI and A GNANAMANI* \\ Microbiology Division, CSIR-Central Leather Research Institute, Adyar, Chennai 600 020, India \\ e-mail: gnanamani3@gmail.com
}

MS received 20 April 2012; revised 2 July 2013; accepted 29 September 2013

\begin{abstract}
In the field of natural and/or synthetic polymer preparation and stabilization, glutaraldehyde is the most commonly used cross-linker. Glutaraldehyde is focused by several scientists due its ease of cross-linking ability through the formation of Schiff base type of compound. Though glutaraldehyde cross-linked product has several advantages, the main drawback lies with the toxicity and poor mechanical stability. The poor mechanical strength of glutaraldehyde cross-linked product is due to the bonding pattern $(-\mathrm{C}=\mathrm{N}-)$ between glutaraldehyde and amine group containing compound, where, there is a large energy barrier to rotation associated with groups joined by double bond. This is the time to search for an alternative cross-linker which will provide a non-toxic and mechanically stable biopolymer material. In order to achieve the requisite property, in the present study, we have chosen glutaric acid (oxidized form of glutaraldehyde) and studied its interaction with chitosan and typeI collagen. The chemistry behind the interaction and the characteristics of the biopolymer material obtained upon cross-linking suggests that non-covalent interactions play a major role in deciding the property of the said materials and its suitability for biomedical applications.
\end{abstract}

Keywords. Ionic cross-linking; glutaric acid; glutaraldehyde; collagen; chitosan.

\section{Introduction}

Recent research on biomaterial development suggests, biopolymers of natural origin find immense clinical applications. And most of the research publications discussed the significant role of natural polymers, chitosan and collagen in biomedical applications. ${ }^{1-4}$ Synthetic polymers possess certain drawbacks, such as high crystallinity, low degradation rate, unfavourable mechanical properties, and immunogenicity according to Bourke and Kohn. ${ }^{5}$ Further, Ko et al. ${ }^{6}$ suggested that use of naturally derived polymers as three-dimensional scaffolds received wide attention due to low cost, ease of processing and biocompatibility. With regard to the chitosan and collagen, both these materials after extraction did not have much stability to act as a biomaterial for clinical applications and demand stabilizers in the form of cross-linkers. Number of cross-linkers ${ }^{7-10}$ were in the reports for the stabilization of these two macromolecules. The stability of the resultant biomaterial upon cross-linking with these agents though highly appreciable, but the complete utilization of these

*For correspondence materials was restricted because of low mechanical strength. The main drawback of existing cross-linkers such as dialdehydes is the toxic nature to cells. ${ }^{11,12}$ For example, glutaraldehyde has been identified as neurotoxic and the impact on the human body has not yet explored completely, ${ }^{13}$ and glyoxal is known to be mutagenic. ${ }^{14}$ Several researchers have chosen glutaraldehyde ${ }^{15,16}$ for cross-linking with chitosan and collagen because of its cross-linking pattern with both natural polymers. The free $-\mathrm{NH}_{2}$ group of chitosan and collagen can easily react with $-\mathrm{C}=\mathrm{O}$ group of glutaraldehyde to form compounds with a carbonnitrogen double bond $(\mathrm{C}=\mathrm{N})$ called imines. The chemistry behind the formation of imine type compound has been given in discussion section. However, glutaraldehyde cross-linked chitosan and collagen-based biopolymer demonstrate less mechanical strength ${ }^{17}$ in addition to cell toxicity. ${ }^{18}$ Since, these two properties are of high importance for the biopolymers, an alternative cross-linking agent is the need of the hour.

With regard to cross-linking of chitosan and collagen with traditional cross-linking agent glutaraldehyde at room temperature, formation of glutaric acid is unavoidable. Hence, it is necessary to study the impact of glutaric acid with chitosan and collagen. 
De-acetylated chitosan was in use for chitosan-based material and for collagen-based materials, type-I collagen of bovine, porcine and fish were in use. Glutaric acid (pentanedioic acid), C-3 organic dicarboxylic acid, is a white crystalline powder with the formula (HOOC $\left.\left(\mathrm{CH}_{2}\right)_{3} \mathrm{COOH}\right)$. Glutaric acid mainly occurs in plant and animal tissues and is found in the blood and urine and finally non-toxic. ${ }^{19}$

Thus, the present study emphasizes, how the effective cross-linking of glutaric acid with natural polymers of chitosan and type-I collagen and further demonstrates the cross-linking chemistry between the molecules using suitable bioinformatics tools. In addition, thermal, mechanical properties and the biocompatibility of the resultant biopolymers also explored in detail.

\section{Experimental}

\subsection{Materials}

Chitosan from shrimp shells ( $\geq 75 \%$ deacetylated), glutaric acid, picrylsulphonic acid [2, 4, 6-trinitrobenzene sulphonic acid (TNBS)], were obtained from SigmaAldrich (USA). 3-[4, 5-Dimethylthiazol-2-yl]-2, 5dephenyltetrazolium bromide (MTT), dexamethasone was purchased from Hi- Media (India). All the other reagents were of analytical reagent grade and used without further purification.

Type-I collagen from bovine skin was extracted according to the procedure followed by Mitra et al. ${ }^{20}$

\subsection{Preparation of biopolymers}

For the preparation of biopolymers using glutaric acid, the following procedure was employed. In this procedure, the use of acetic acid for dissolution of natural polymers like Chitosan and collagen was completely avoided. In brief, the powder form of chitosan (1\%) and type-I collagen $(0.5 \%)(\mathrm{w} / \mathrm{v})$ was individually added to $20 \mathrm{ml}$ of water taken in the glass beakers and stirred vigorously to ensure the uniform distribution. To that dispersed mixture, glutaric acid was added and the stirring was continued for an hour. Concentration of glutaric acid (GA) was varied between 0.05 and $0.5 \%$ $(\mathrm{w} / \mathrm{v})$. Collagen sample was stirred at $4^{\circ} \mathrm{C}$, whereas, ambient temperature was given for chitosan samples. Followed by stirring, the samples were subjected to centrifugation and a clear solution obtained upon centrifugation at 5,000 rpm for $10 \mathrm{~min}$ was poured in Tarson (India) vial of an inner diameter of $4.5 \mathrm{~cm}$ and frozen at $-4^{\circ} \mathrm{C}$ for $2 \mathrm{~h},-20^{\circ} \mathrm{C}$ for $12 \mathrm{~h}$ and $-80^{\circ} \mathrm{C}$ for another $12 \mathrm{~h}$. The frozen samples were lyophilized for $48 \mathrm{~h}$ at vacuum of 7.5 militorr (1 Pa) and a condenser temperature of $-70^{\circ} \mathrm{C}$ (PENQU CLASSIC PLUS, Lark, India). The resultant 3D scaffold biopolymer material was neutralized with repeated washings with $0.05 \mathrm{~N}$ $\mathrm{NaOH} /$ ethanol mixture followed by washings with water/ethanol mixture (to remove the unreacted chemicals) and finally again lyophilized for $24 \mathrm{~h}$. The scaffold obtained in this procedure was designated as $\mathrm{GACCH}$ (glutaric acid cross-linked chitosan) and GACC (glutaric acid cross-linked collagen).

For comparative analysis, glutaraldehyde crosslinked chitosan scaffold (GADCCH) and glutaraldehyde cross-linked collagen scaffold (GADCC) were prepared according to the method described in the above said paragraph using $0.2 \%$ glutaraldehyde.

\subsection{Texture and morphology of the biopolymers}

The physical texture and the morphology of the biopolymers of glutaric acid cross-linked chitosan and collagen was assessed using physical touch followed by scanning electron micrograph (SEM). SEM micrograph analysis was made using F E I Quanta FEG 200 - High Resolution Scanning Electron Microscope instrument under high voltage at $20 \mathrm{kV}$.

\subsection{Analysis of functional groups}

Functional group analysis (FT-IR) for GA, chitosan, type-I collagen, GACCH and GACC biopolymers were made by spectrum one (Perkin-Elmer Co., USA model) FT- IR instrument. All spectra were recorded with the resolution of $4 \mathrm{~cm}^{-1}$ in the range of $400-4000 \mathrm{~cm}^{-1}$

\subsection{Estimation of percentage of cross-linking degree (TNBS assay)}

The degree of cross-linking was quantified using TNBS assay. ${ }^{21}$ In brief, chitosan, type-I collagen, GACCH and GACC biopolymers were cut into small pieces of size $4.5 \mathrm{~mm}$. Six milligrams of cut pieces were immersed in $2 \mathrm{ml}$ solution $[1 \mathrm{ml}$ of $4 \%(\mathrm{w} / \mathrm{v})$ di-sodium hydrogen orthophosphate and $1 \mathrm{ml}$ of $0.5 \%(\mathrm{v} / \mathrm{v}) \mathrm{TNBS}]$, and incubated at $40^{\circ} \mathrm{C}$ for $2 \mathrm{~h}$. The reaction was terminated by the addition of $3 \mathrm{ml}$ of $6 \mathrm{M} \mathrm{(v/v)} \mathrm{HCl}$ and the incubation was continued at $60^{\circ} \mathrm{C}$ for $90 \mathrm{~min}$. The percentage of cross-linking degree was calculated from the difference in the absorbance divided by the absorbance of the native material (chitosan and type I collagen) and then multiplied with 100 . The absorbance of the resulting solution was measured at $345 \mathrm{~nm}$ using UV-Visible spectrophotometer. 


\subsection{Analysis of mechanical properties of GACCH, GACC, GADCCH and GADCC biopolymers}

Mechanical properties, viz., Young's modulus, ultimate tensile strength, stiffness and percentage of elongation of the dried scaffold biopolymers were measured using Universal Testing Machine (INSTRON model 1405) at a cross head speed of $5 \mathrm{~mm} \mathrm{~min} \mathrm{~m}^{-1}$ at $25^{\circ} \mathrm{C}$ and $65 \%$ relative humidity. Length and width of the dumbbellshaped test sample was maintained as 20 and $5 \mathrm{~mm}$, respectively. All the mechanical tests were performed with dried samples and were examined in triplicate way.

\subsection{Thermo gravimetric analysis (TGA)}

Thermal decomposition analysis of GA, native and cross-linked biopolymers (chitosan, type-I collagen, GACCH, GACC, GADCCH and GADCC) were carried out under nitrogen flow (40 and $60 \mathrm{ml} \mathrm{min}^{-1}$ ) with ramp $20^{\circ} \mathrm{C} \mathrm{min}^{-1}$ using TGA Q 50(V20.6 build 31) instrument.

\subsection{Differential scanning calorimetry (DSC)}

Thermal properties of GA, native and cross-linked biopolymers (chitosan, type-I collagen, GACCH, GACC, GADCCH and GADCC) were analysed using differential scanning calorimeter, model -DSC Q 200(V 23.10 Build 79) with standard mode at nitrogen $(50 \mathrm{ml}$ $\mathrm{min}^{-1}$ ) atmosphere with $\operatorname{ramp} 10^{\circ} \mathrm{C} \mathrm{min}^{-1}$.

\subsection{Binding energy calculations} using Bioinformatics tools

For the docking study, chemical structures of chitosan and GA were generated using ACD/ChemSketch ${ }^{22}$ (ACD/ChemSketch Version 12, Advanced Chemistry Development, Inc., Toronto, ON, Canada. 2009) and according to Madhan et al. ${ }^{23}$ the three-dimensional structure of type-I collagen was generated using GENCOLLAGEN program. ${ }^{24}$ Docking technique is useful to find out the binding efficiency with ligand and a chemical compound. To find out the interaction between chitosan and type-I collagen with GA, AUTODOCK has been used and AutoDock 4.2 used to calculate ${ }^{25}$ the free energy of binding of GA with chitosan and type-I collagen. It is faster than other versions and force field includes an updated chargebased desolvation term, improvements in the directionality of hydrogen bonds, and several improved models of the unbound state. Current procedure categorized under semi-flexible docking protocol in that chitosan and type-I collagen were kept as rigid and ligands being docked were kept flexible; Kollman united atom charges, salvation parameters and polar hydrogens were added with chitosan PDB file for the polysaccharide, in ligands Gasteiger charges were assigned and then nonpolar hydrogen was merged before docking simulation. Total numbers of rigid roots were defined using automatically with amide bond kept as non-rotatable. The possible dihedrals in the ligand are allowed to rotate freely using Auto-Tors. Pre-calculated grid maps for each atom in the ligand were generated using Autogrid. The $5 \AA$ grid was built surrounding the binding pocket. Three-dimensional grids of interaction energy for all possible atom types that were already present in the Auto Dock default parameter set were calculated. This grid maps were of dimension $60 \times 60 \times 60$ points with the spacing of $0.375 \AA$ yielding a receptor model that included atoms within $0.5 \AA$ of the grid centre. The Graphical User Interface program 'Auto-Dock Tools' was used to prepare, run and analyse the docking simulations. The Lamarckian Genetic Algorithm (LGA) was chosen to search for the best conformers.

\subsection{In vitro assessment on cell compatibility of the biopolymers GACCH and GACC}

Biocompatibility in terms of cytotoxicity, cell proliferation, live cell detection and cell attachment on the prepared scaffold biopolymers were analysed using NIH $3 \mathrm{~T} 3$ fibroblast cell line. According to Trentani et al. ${ }^{26}$ this cell line is a robust and durable platform for investigating common cellular functions: attachment, viability, proliferation and cellular properties etc.

\subsection{Cell proliferation study (MTT assay)}

Cells were grown in DMEM (Dulbecco's modified Eagle's medium) supplemented with $10 \%(\mathrm{v} / \mathrm{v})$ foetal bovine serum and $1 \%$ antibiotic and were incubated at $37^{\circ} \mathrm{C}$ in $5 \% \mathrm{CO}_{2}$ humidified atmosphere. Polystyrene 96 well culture plates (Tarson, India) were coated with native chitosan, type-I collagen, GA cross-linked chitosan (GACCH), type-I collagen (GACC), glutaraldehyde (GAD) cross-linked chitosan $(\mathrm{GADCCH})$ and type-I collagen (GADCC) biopolymers. The plates were dried under laminar air flow hood followed by UV sterilization. The cells were seeded at the density of $5 \times 10^{3}$ cells per well and incubated at $37^{\circ} \mathrm{C}$ in a humidified atmosphere containing $5 \% \mathrm{CO}_{2}$. At scheduled time points of 24, 48, and $72 \mathrm{~h}$, the supernatant of each well was replaced with MTT diluted in serum-free medium and the plates incubated at $37^{\circ} \mathrm{C}$ for $4 \mathrm{~h}$. After removing 
the MTT solution, acid isopropanol $(0.04 \mathrm{~N} \mathrm{HCl}$ in isopropanol) was added to each well and pipetted up and down to dissolve all of the dark blue crystals and then left at room temperature for a few minutes to ensure all crystals are dissolved. Finally, absorbance was measured at $570 \mathrm{~nm}$ using UV spectrophotometer. ${ }^{27}$ The experiment was performed at least three times. The sets of three wells for the MTT assay were used for each experimental variant.

\subsection{Cell tracker assay to detect live cells}

Cell viability was measured using 5-chloromethylfluorescein diacetate probe (CMFDA) (Invitrogen). NIH 3T3 cells were subjected to respective treatment conditions. Cells were probed with $5 \mu \mathrm{M}$ CMFDA and incubated for $2 \mathrm{~h}$. Cells were then washed with sterile PBS and images were taken using DP71 camera adapted to an Olympus IX71 microscope. ${ }^{28}$

\subsection{Cell growth and morphology of NIH 3 T3 cells in GACCH and GACC biopolymers}

GACCH and GACC scaffolds $(2 \times 2 \times 1 \mathrm{~cm})$ were placed individually in 6 well culture plates (Tarson, India) and ETO (Ethylene Oxide) sterilized. Culture media was added to the scaffolds for overnight. NIH 3 T3 fibroblast cells were seeded onto the scaffolds at a density of $5 \times 10^{4}$ cells and incubated in an atmosphere of $5 \% \mathrm{CO}_{2}$ at $37^{\circ} \mathrm{C}$. The medium was changed every $24 \mathrm{~h}$. Morphology of the cells were examined after 12 days according to the following procedure. The cells-scaffold constructs were fixed in $2.5 \%$ glutaraldehyde and dehydrated through graded ethanol series. ${ }^{29}$ The dried cells-scaffold were coated with gold (E-1010 Ion sputter, HITACHI) and examined under SEM (S-3400 N Scanning Electron Microscope HITACHI).

\section{Results and discussion}

As described in the Introduction, cross-linkers are used to stabilize natural polymer materials for biomedical applications. Glutaraldehyde is the maximum choice compared to other cross-linkers. However, the recent realization of the toxicity and the mechanical properties of glutaraldehyde cross-linked biopolymers necessitates the alternative cross-linkers. In the present study, suitability of glutaric acid as cross-linker was evaluated using two natural polymers and in addition understanding the chemistry behind the interactions.

\subsection{Biopolymer preparation using glutaric acid: Understanding the cross-linking chemistry}

For the preparation of any biopolymer materials, the solution form of parent compound/polymer is required to proceed further. However, in the case of chitosan and collagen, two natural polymers chosen for the present study were insoluble in water and acetic and formic acids were used for dissolution. ${ }^{30,31}$ The "proton exchange' between $-\mathrm{COOH}$ groups of acid molecule

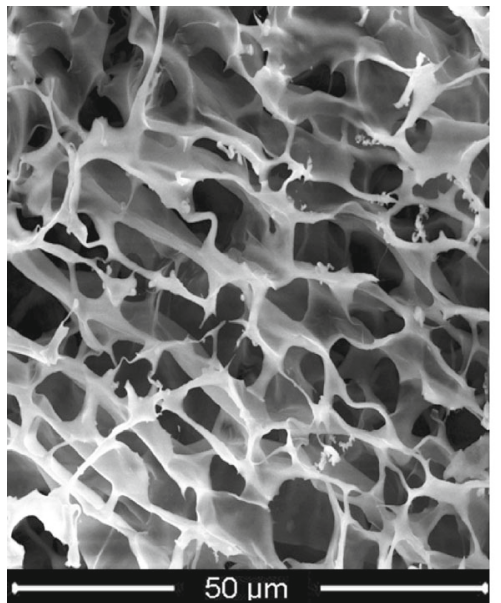

(a)

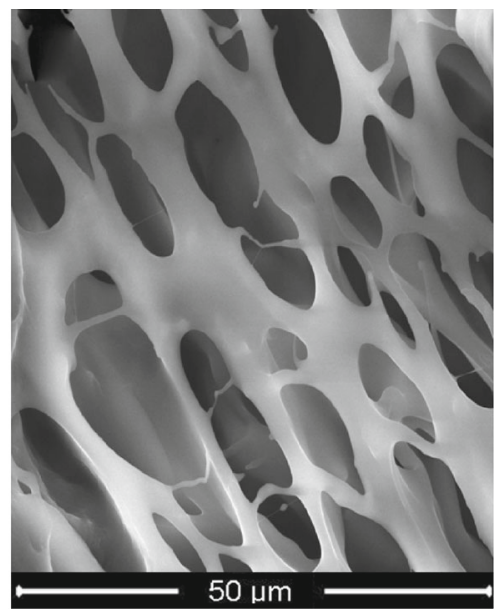

(b)

Figure 1. (a) SEM micrographs of glutaric acid cross-linked chitosan $(\mathrm{GACCH})$ and (b) glutaric acid cross-linked collagen (GACC) biopolymers. 
and free $-\mathrm{NH}_{2}$ groups of chitosan and collagen could be reasoned for the dissolution in the said acids.

Therefore, it has been expected that like acetic acid, glutaric acid is also able to provide protons to dissolve chitosan and type-I collagen. Further, alike interaction of TPP (tripolyphosphate) ${ }^{32}$ with chitosan, glutaric acid also interacts with both the natural polymers through ionic interaction. Because of the said proton exchange,

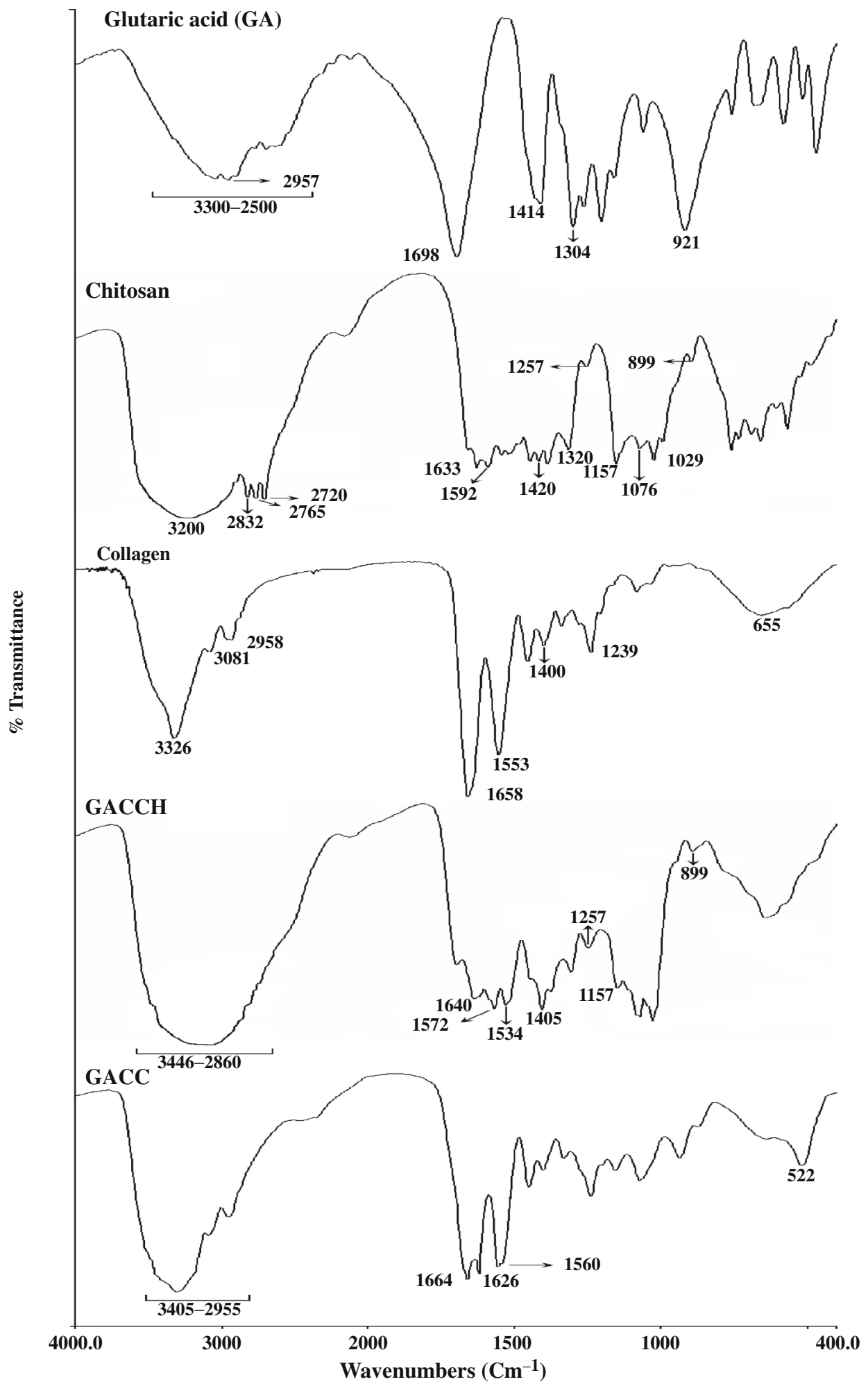

Figure 2. FT-IR spectrum of glutaric acid (GA), Chitosan, type-I collagen, glutaric acid cross-linked chitosan (GACCH) and glutaric acid cross-linked collagen (GACC) biopolymers. 
Table 1. FT-IR analysis of glutaric acid, chitosan and collagen.

\begin{tabular}{|c|c|}
\hline Wavenumber $\left(\mathrm{cm}^{-1}\right)$ & Peak assignment \\
\hline & Glutaric acid \\
\hline $3300-2500$ & Broad O-H stretch $\left(v_{\mathrm{O}-\mathrm{H}}\right)$ \\
\hline 2957 & $-\mathrm{CH}_{2}$ stretch $\left(v_{\mathrm{C}-\mathrm{H}}\right)$ superimposed upon $\mathrm{O}-\mathrm{H}$ stretch \\
\hline 1698 & Carboxylic $-\mathrm{C}=\mathrm{O}$ group stretch $\left(v_{\mathrm{C}=\mathrm{O}}\right)$ \\
\hline 1414 & $\mathrm{C}-\mathrm{O}-\mathrm{H}$ in-plane bending $\left(\delta_{\mathrm{C}-\mathrm{O}-\mathrm{H}}\right)$ \\
\hline 1304 & $\mathrm{C}-\mathrm{O}$ stretching vibration $\left(v_{\mathrm{C}-\mathrm{O}}\right)$ \\
\hline \multirow[t]{2}{*}{921} & Out- of- plane bending of the bonded $\mathrm{O}-\mathrm{H}\left(\delta_{\mathrm{O}-\mathrm{H}}\right)$ \\
\hline & Chitosan \\
\hline 3200 & $-\mathrm{NH}_{2}$ stretching vibration $\left(v_{\mathrm{NH}}\right)$ \\
\hline $2832,2765,2720$ & $\begin{array}{l}\text { Symmetric or asymmetric }-\mathrm{CH}_{2} \text { stretching vibration } \\
\text { attributed to pyranose ring }\left(v_{\mathrm{C}-\mathrm{H}}\right)\end{array}$ \\
\hline 1633 & $-\mathrm{C}=\mathrm{O}$ in acetamide group (amide $\mathrm{I}$ band) \\
\hline 1592 & $-\mathrm{NH}_{2}$ bending vibration in amino group $\left(\delta_{\mathrm{NH}}\right)$ \\
\hline 1420,1320 & Vibrations of $\mathrm{OH}, \mathrm{CH}$ in the ring \\
\hline 1257 & $\mathrm{C}-\mathrm{O}$ group \\
\hline 1157 & $-\mathrm{C}-\mathrm{O}-\mathrm{C}$ in glycosidic linkage \\
\hline 1076,1029 & $\mathrm{C}-\mathrm{O}$ stretching in acetamide $\left(v_{\mathrm{C}-\mathrm{O}}\right)$ \\
\hline \multirow[t]{2}{*}{899} & Corresponds to saccharide structure \\
\hline & Collagen \\
\hline 3326 & $-\mathrm{NH}_{2}$ stretching vibration $\left(v_{\mathrm{NH}}\right)$ \\
\hline 3081 & Fermi resonance overtone of 1553 band \\
\hline 2958 & $\mathrm{C}-\mathrm{H}$ stretching $\left(v_{\mathrm{C}-\mathrm{H}}\right)$ \\
\hline 1658 & Amide I band $\left(v_{\mathrm{C}=\mathrm{O}}\right)$ \\
\hline 1553 & Amide II band $\left(\delta_{\mathrm{NH}}\right)$ \\
\hline 1400 & Amide III band $\left(v_{\mathrm{C}-\mathrm{N}}\right)$ \\
\hline 1239 & $\mathrm{C}-\mathrm{N}$ stretching of amine $\left(v_{\mathrm{C}-\mathrm{N}}\right)$ \\
\hline 655 & Out-of-plane $\mathrm{N}-\mathrm{H}$ wagging of amide and amine $\left(\delta_{\mathrm{NH}}\right)$ \\
\hline
\end{tabular}

$\nu$ - stretching; $\delta$ - bending

chitosan and type-I collagen get dissolved in the presence of glutaric acid in water. The ionic interaction and the hydrogen bonding between $-\mathrm{COOH}$ group of cross-linker and $-\mathrm{NH}_{2}$ group of chitosan/collagen was already in reports. ${ }^{33-36}$

Because of the said ionic interactions, both the natural polymers completely dissolved in water in the presence of glutaric acid. With the resulting solution, scaffolds were prepared and subjected to characterization studies. Figure 1 demonstrates the morphological features of the cross-linked biopolymers $(\mathrm{GACCH}$ and GACC). The 3D biopolymer material was highly porous and the pore structures of the membranes were well-distributed and interconnected. It was obvious that most of the volume of the membranes were taken up by the interconnecting pore space. The high porosity

Table 2. Measurement of cross-linking degree of glutaric acid cross-linked chitosan (GACCH) and glutaric acid crosslinked collagen $(\mathrm{GACC})$ prepared using different concentrations of glutaric acid $(0.05-0.5 \%)$.

\begin{tabular}{lcc}
$\begin{array}{l}\text { Concentration of } \\
\text { glutaric acid }(\%, \mathrm{w} / \mathrm{v})\end{array}$ & $\begin{array}{c}\text { Percentage of cross-linking } \\
\text { degree of GACCH }(\%)\end{array}$ & $\begin{array}{c}\text { Percentage of cross-linking } \\
\text { degree of GACC }(\%)\end{array}$ \\
\hline 0.05 & 53.6 & 53.8 \\
0.1 & 54.4 & 58.6 \\
0.2 & 64.2 & 66.4 \\
0.3 & 70.5 & 75.3 \\
0.4 & 72.4 & 75.5 \\
0.5 & 72.5 & 75.8 \\
\hline
\end{tabular}


Table 3. Assessment of mechanical properties of chitosan, glutaric acid cross-linked chitosan (GACCH), collagen and glutaric acid cross-linked collagen (GACC) in terms of tensile strength, elongation at break, and young's modulus.

\begin{tabular}{lccccc}
\hline Samples & $\begin{array}{c}\text { Maximum } \\
\text { load(N) }\end{array}$ & $\begin{array}{c}\text { Tensile } \\
\text { strength(MPa) }\end{array}$ & $\begin{array}{c}\text { Elongation at } \\
\text { break (\%) }\end{array}$ & $\begin{array}{c}\text { Extension at maximum } \\
\text { load (mm) }\end{array}$ & $\begin{array}{c}\text { Young's modulus/tensile } \\
\text { modulus(MPa) }\end{array}$ \\
\hline Chitosan & 1.32 & 0.37 & 8.33 & 1.67 & 4.43 \\
GACCH & 1.59 & 1.67 & 120.75 & 24.15 & 1.38 \\
Collagen & 0.37 & 0.13 & 6.17 & 1.23 & 2.114 \\
GACC & 4.20 & 9.34 & 12.46 & 2.49 & 75.02 \\
\hline
\end{tabular}

suggests the suitability of this biopolymer for biomedical applications, including serving as absorption sponges and matrices for cell proliferation.

FT-IR analysis was conducted to monitor the chemical modifications in chitosan and collagen structures due to cross-linking with GA. Figure 2 illustrates the FT-IR spectral details of GA, chitosan, collagen, GACCH and GACC. Table 1 demonstrates the FTIR peak assignments of GA, chitosan and collagen. In $\mathrm{GACCH}$ spectrum few significant changes were observed. A broad, strong absorption in the region of $3446-2860 \mathrm{~cm}^{-1}$ was resulting from superimposed $-\mathrm{OH}$ and $-\mathrm{NH}_{3}^{+}$stretching band. Absorption at 1640 and $1572 \mathrm{~cm}^{-1}$ correspond to the presence of asymmetric $\mathrm{N}-\mathrm{H}\left(-\mathrm{NH}_{3}^{+}\right)$bend and asymmetric $-\mathrm{COO}^{-}$stretching, respectively, Peak observed at 1534 and $1405 \mathrm{~cm}^{-1}$ was due to symmetric $\mathrm{N}-\mathrm{H}\left(-\mathrm{NH}_{3}^{+}\right)$bend and symmetric $-\mathrm{COO}^{-}$stretching, respectively. Other absorption peaks around 1257, 1157 and $899 \mathrm{~cm}^{-1}$ observed in GACCH spectrum were similar to the native chitosan spectrum which exhibits that there was no change in main backbone of chitosan structure.

In GACC spectrum few changes were observed when compared to native type-I collagen this could be due to the cross-linking of type-I collagen with GA. A broad, strong absorption in the region of 3405-
$2955 \mathrm{~cm}^{-1}$ was resulting from superimposed $-\mathrm{CH},-\mathrm{OH}$ and $-\mathrm{NH}_{3}^{+}$stretching band. In type-I collagen spectrum a sharp intense amide-I band was observed at around $1658 \mathrm{~cm}^{-1}$ which was disappeared with the appearance of two new bands at 1664 and $1626 \mathrm{~cm}^{-1}$ in GACC spectrum, these bands were supposed to be caused by the $-\mathrm{NH}_{3}^{+}$and $-\mathrm{COO}^{-}$, respectively. Moreover, when compared with native type-I collagen spectrum, in GACC spectrum there is a reduction in the region of $1560 \mathrm{~cm}^{-1}$ (overlapped band of amide II and free primary amines) which may be due to the reduction of free $-\mathrm{NH}_{2}$ group in GACC. In GACC spectra, band around $522 \mathrm{~cm}^{-1}$ was observed which was ascribed to the $\mathrm{N}-\mathrm{H}$ oscillation of $-\mathrm{NH}_{3}^{+}$. Results from FT-IR analysis reflected that GA was ionically cross-linked with chitosan and type-I collagen. ${ }^{37}$

Though FT-IR analysis displayed the ionic interaction between the cross-linker and the natural polymers, results on the percentage of cross-linking degree suggests that increasing the concentration of glutaric acid increases the degree of cross-linking up to $0.4 \%$ and confirmed the interaction. Table 2 shows the percentage of cross-linking degree for chitosan and collagen in the presence of increasing concentration of glutaric acid. About $60-66 \%$ cross linking was observed with $0.2 \%$ glutaric acid with chitosan and collagen. However,

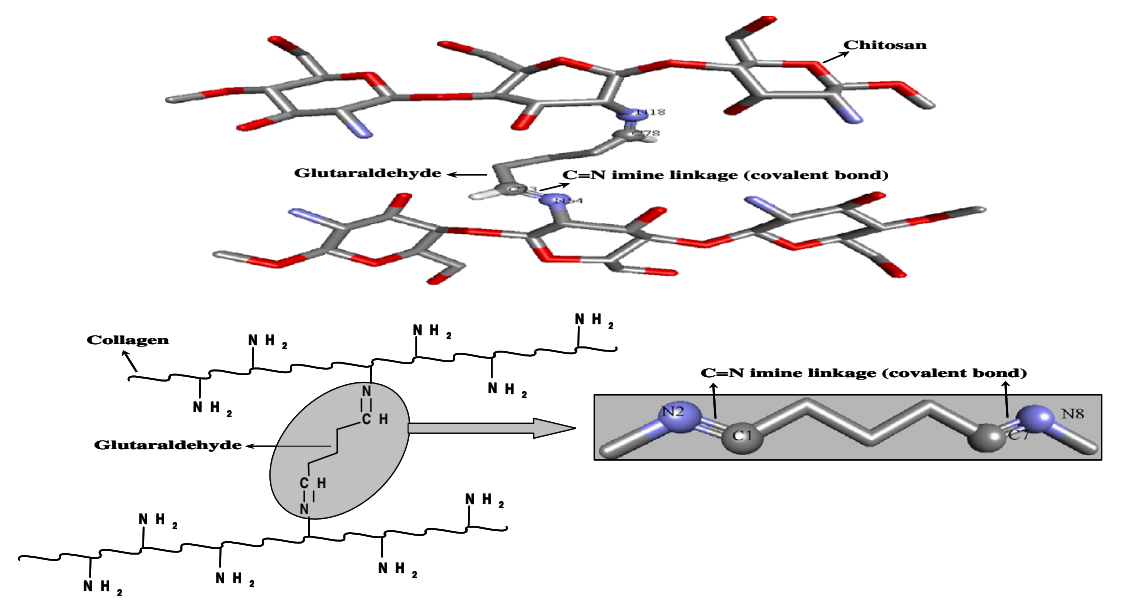

Scheme 1. Interaction of glutraldehyde wth chitosan and collagen. 

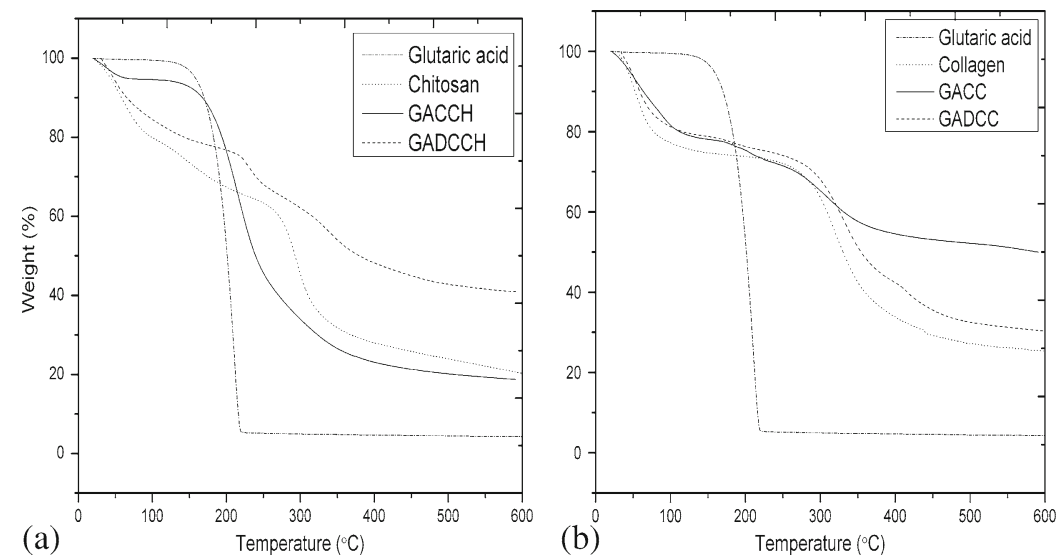

Figure 3. (a) Thermo gravimetric analysis of glutaric acid (GA), chitosan, glutaric acid cross-linked chitosan $(\mathrm{GACCH})$ and glutaraldehyde cross-linked chitosan (GADCCH) biopolymers. (b) Thermo gravimetric analysis of GA, collagen, glutaric acid cross-linked collagen (GACC) and glutaraldehyde cross-linked collagen (GADCC) biopolymers.

in the case of experiments with glutaraldehyde, about $88-93 \%$ of cross-linking was observed with $0.2 \%$ concentration of glutaraldehyde.

With regard to mechanical property of the biopolymer materials, the mechanical property is a fundamental property for any biopolymer in application point of view. From the results, we observed that the mechanical strength of the biopolymer was increased with an increase in glutaric acid concentration up to $0.2 \%$. Further increase in GA concentration leads to the decrease in mechanical strength (results not shown). Table 3 illustrates tensile strength, young's modulus, stiffness of native and glutaric acid (0.2\%) cross-linked biopolymers and supplementary figure S1 demonstrates the stress strain curve of chitosan, GACCH, collagen and GACC. High tensile strength (MPa) values were observed for both the cross-linked biopolymers (GACCH- 1.67 and GACC- 9.34) compared to the native polymers (chitosan- 0.37 and type-
I collagen - 0.13). Moreover the young's modulus of GACCH and GACC were 1.38 and 75.02, respectively. The stiffness values (GACCH- 0.066 and GACC$1.68 \mathrm{~N} / \mathrm{mm}$ ) were also greater than that of the native biopolymers (chitosan- 0.79 and type-I collagen $0.3 \mathrm{~N} / \mathrm{mm}$ ).

All these observations on mechanical properties suggest, glutaric acid cross-linked biopolymer materials demonstrate appreciable mechanical strength compared to glutaraldehyde, where, we observed brittleness. Schiffman et al. ${ }^{17}$ reported brittle nature of the biomaterial upon cross-linking with glutaraldehyde. Further, when the concentration of GA was increased $>0.2 \%$, a decrease in mechanical strength was observed and this could be reasoned to the high degree of cross-linking of GA with the biopolymers which is clearly proved from the results of TNBS assay. ${ }^{38}$ In the same manner, with the high cross-linking degree, glutaraldehyde display materials with brittle nature.

Table 4. Thermal analysis of glutaric acid (GA), chitosan, glutaric acid cross-linked chitosan (GACCH), glutaraldehyde cross-linked chitosan (GADCCH), collagen, glutaric acid cross-linked collagen (GACC) and glutaraldehyde cross-linked collagen (GADCC) under $\mathrm{N}_{2}$ air atmosphere.

\begin{tabular}{lccccccc}
\hline & \multicolumn{7}{c}{ \% of weight loss (heating rate $\left.20^{\circ} \mathrm{C} / \mathrm{min}\right)$} \\
\cline { 2 - 8 } Temperature $\left({ }^{\circ} \mathrm{C}\right)$ & Glutaric acid & Chitosan & GACCH & GADCCH & Collagen & GACC & GADCC \\
\hline 100 & 0 & 21 & 5 & 16 & 23 & 20 & 20 \\
200 & 48 & 33 & 24 & 24 & 27 & 25 & 24 \\
300 & 96 & 56 & 66 & 38 & 37 & 35 & 33 \\
400 & 96 & 73 & 77 & 52 & 67 & 46 & 58 \\
500 & 96 & 77 & 80 & 58 & 73 & 48 & 68 \\
600 & 96 & 81 & 81 & 60 & 75 & 50 & 70 \\
\hline
\end{tabular}



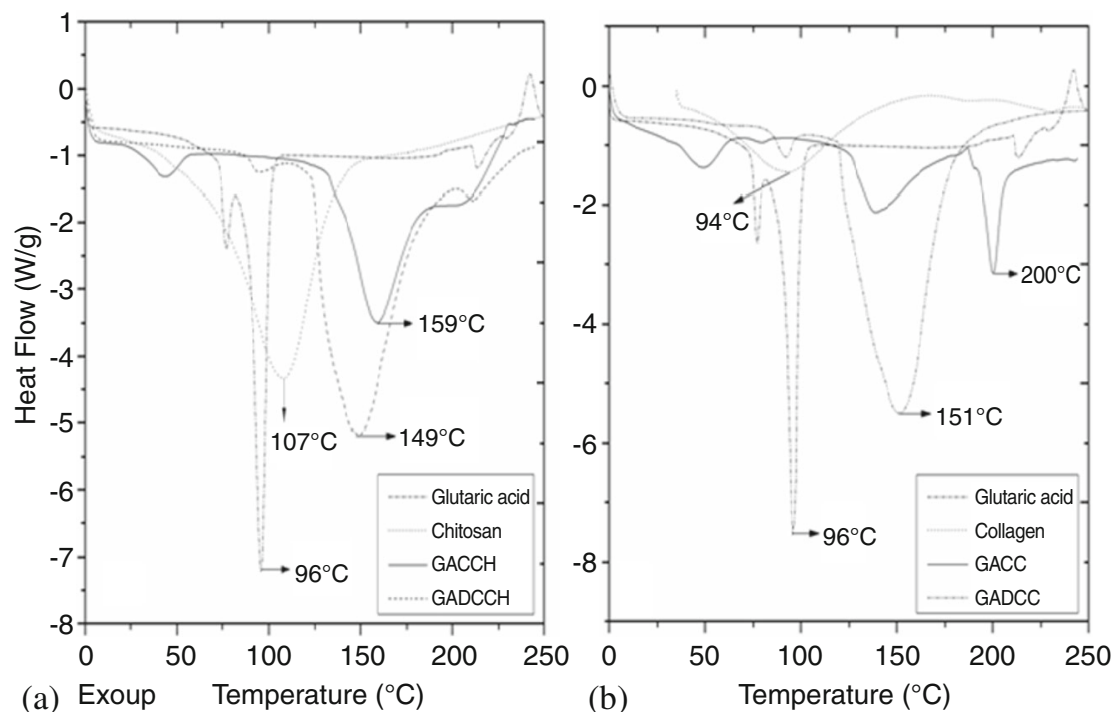

Figure 4. (a) Differential scanning calorimetry analysis of glutaric acid (GA), chitosan, glutaric acid cross-linked chitosan (GACCH) and glutaraldehyde cross-linked chitosan (GADCCH) biopolymers. (b) Differential scanning calorimetry analysis of glutaric acid (GA), collagen, glutaric acid crosslinked collagen (GACC) and glutaraldehyde cross-linked collagen (GACC) biopolymers.

The following schematic (scheme 1) illustrations emphasize the cross-linking chemistry of glutaraldehyde with the chosen natural polymers and reasons out the brittle nature.

The above illustrations suggested that glutaraldehyde could covalently cross-linked with chitosan and collagen through the formation of double bond $(\mathrm{C}=\mathrm{N}$, imine bond) between - $\mathrm{CHO}$ group of glutaraldehyde and $-\mathrm{NH}_{2}$ group of polymers (chitosan and collagen), results with the large energy barrier for rotation of associated groups linked by a double bond $(\mathrm{C}=\mathrm{N})$ and finally provided brittle nature to the biopolymer material.
Thermo gravimetric analysis for the experimental samples GA, chitosan, type-I collagen, GACCH, GACC, GADCCH and GADCC were illustrated in figure $3 \mathrm{a}$ and $\mathrm{b}$ and the corresponding thermal degradation values were given in table 4 . From the results we observed that incorporation of glutaric acid with chitosan and type-I collagen tends to shift the thermal region to a higher temperature and such a shift is attributed to an increase in thermal stability.

Differential scanning calorimetry (DSC) studies were performed to understand the behaviour of GACCH and GACC on application of thermal energy. The thermo grams of GA, chitosan, type-I collagen, GACCH,

Table 5. Binding energy values of glutaric acid cross-linked chitosan (GACCH) and glutaric acid cross-linked collagen (GACC) biopolymers.

\begin{tabular}{|c|c|c|}
\hline Rank & Binding energy (Kcal/mol) & No. of runs \\
\hline \multicolumn{3}{|c|}{ The binding energy calculation between chitosan and glutaric acid based on autodock tool software } \\
\hline 1 & -4.48 & 54 \\
\hline 2 & -4.25 & 13 \\
\hline 3 & -4.18 & 55 \\
\hline 4 & -3.99 & 67 \\
\hline 5 & -3.84 & 57 \\
\hline 6 & -3.75 & 58 \\
\hline \multicolumn{3}{|c|}{ The binding energy calculation between type-I collagen and glutaric acid based on autodock tool software } \\
\hline 1 & -4.28 & 46 \\
\hline 2 & -4.26 & 6 \\
\hline 3 & -3.86 & 3 \\
\hline 4 & -3.62 & 84 \\
\hline
\end{tabular}


GACC, GADCCH and GADCC were shown in figure $4 \mathrm{a}$ and $\mathrm{b}$. DSC studies recorded melting temperature differences among $\mathrm{GA}\left(96^{\circ} \mathrm{C}\right)$, chitosan $\left(107^{\circ} \mathrm{C}\right)$, type-I collagen $\left(94^{\circ} \mathrm{C}\right)$, GACCH $\left(159^{\circ} \mathrm{C}\right)$ and GACC $\left(200^{\circ} \mathrm{C}\right)$, whereas in GADCCH and GADCC it was observed at 149 and $151^{\circ} \mathrm{C}$, respectively. The higher transition temperature suggests, GACCH and GACC had higher stability at high temperature environment. The thermal stability also influences on the durability of the biopolymers. Similar kind of observation was reported by Bhumkar et al. ${ }^{32}$

Results on binding energy calculations based on bioinformatics tool for the cross-linking of GA with chitosan and type-I collagen using Auto Dock software proved that chitosan and type-I collagen can cross-link with glutaric acid not only with ionic interaction but also through multiple intermolecular hydrogen bonding. Autodock is an automated procedure for predicting the interaction of ligands with bio-macromolecular targets. Hundred runs were given for docking GA with chitosan and type-I collagen. The best binding energy values and their corresponding rank and run numbers were depicted in table 5. The binding energy of -4.48 and $-4.28(\mathrm{kcal} / \mathrm{mol})$ was observed when GA were interacted with chitosan and type-I collagen, respectively. These interactions were made by multiple intermolecular hydrogen bonds between - $\mathrm{COOH}$ group of
GA and $-\mathrm{NH}_{2}$ group of chitosan and free $\varepsilon-\mathrm{NH}_{2}$ group of lysine from type-I collagen (figure $5 \mathrm{a}$ and $\mathrm{b}$ ). In addition to ionic cross-linking, hydrogen bonding interaction can also improve the mechanical property of the biopolymer. The details of these intermolecular hydrogen bonding sites were given below.

\subsection{Intermolecular hydrogen bond details between GA and chitosan}

(i) $\mathrm{H}$ (2) of GA is linked with $\mathrm{N}$ (20) of chitosan with the bond distance of 2.40437 .

(ii) $\mathrm{H}$ (6) of chitosan is linked with $\mathrm{O}$ (8) of GA with the bond distance of 2.39196 .

(iii) $\mathrm{H}$ (1) of GA is linked with N (20) of chitosan with the bond distance of 2.39468 .

(iv) $\mathrm{H}$ (6) of chitosan is linked with $\mathrm{O}$ (5) of GA with the bond distance of 1.87394 .

(v) $\mathrm{H}$ (7) of chitosan is linked with O (4) of GA with the bond distance of 2.11166 .

\subsection{Intermolecular hydrogen bond details between GA and type-I collagen}

(i) LYS (12) H of type-I collagen is linked with O (9) of GA with the bond distance of 1.68012 .
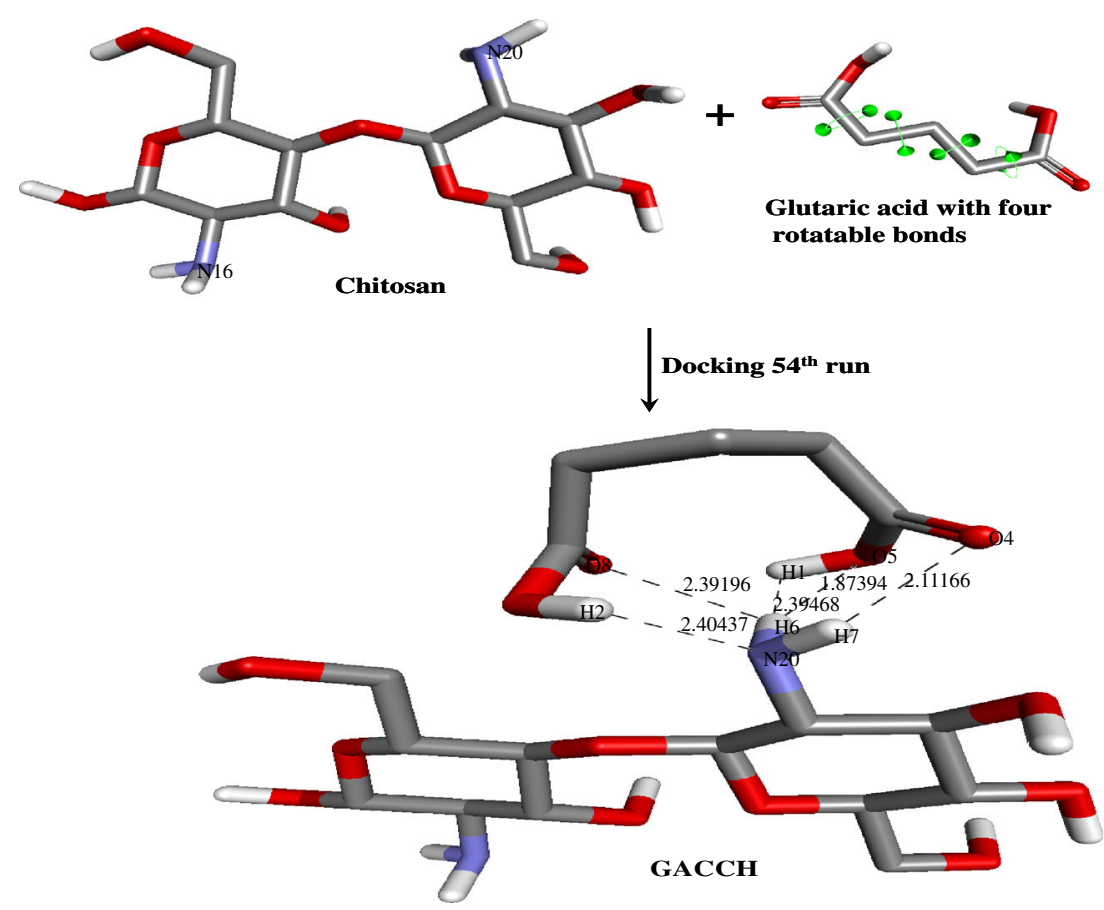

(a)

Figure 5a. Multiple hydrogen bonding interaction between chitosan and glutaric acid (GA). 


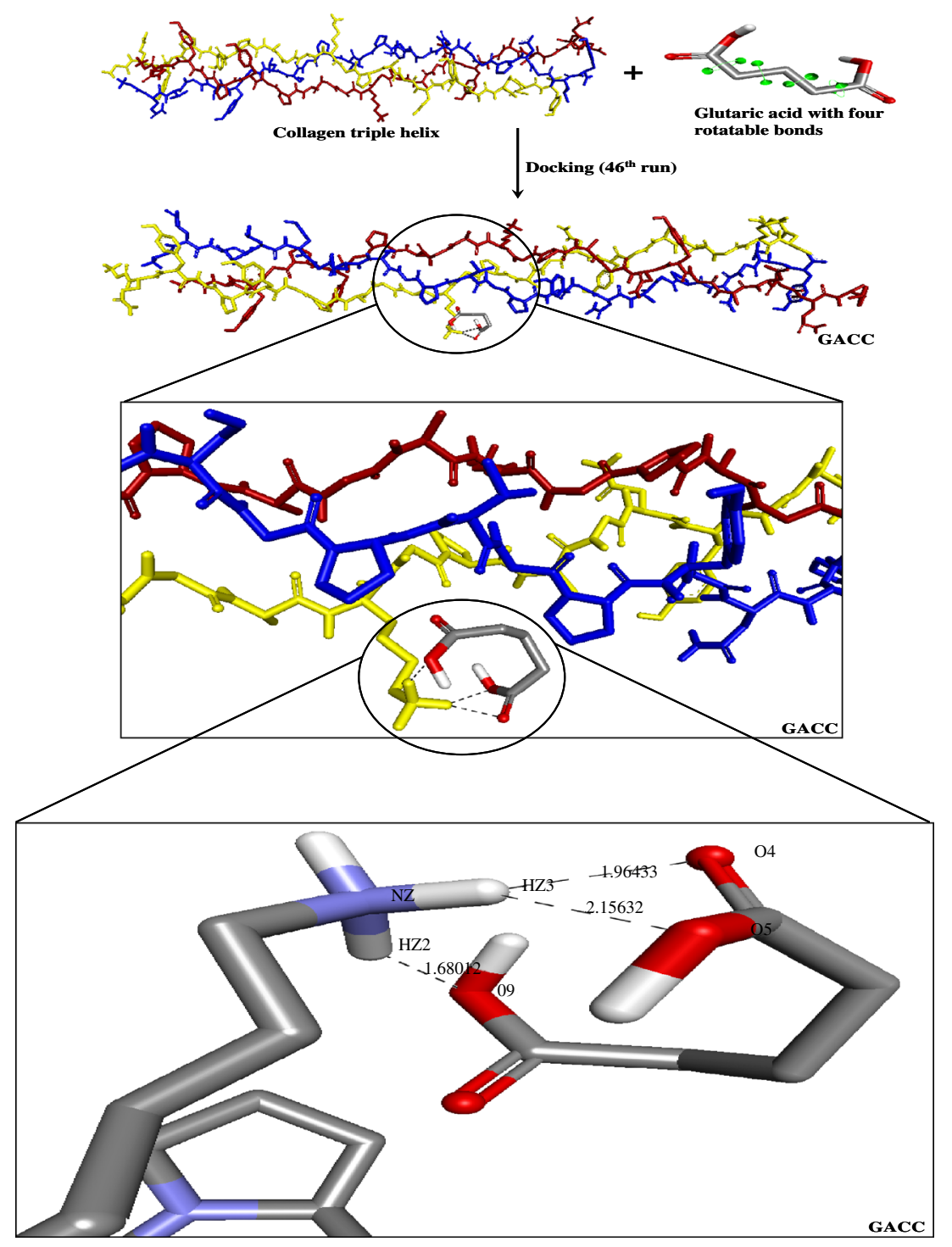

(b)

Figure 5b. Multiple hydrogen bonding interaction between collagen and glutaric acid (GA). (The black dotted line indicates the hydrogen bond. In figure white colour is for hydrogen atom $(\mathrm{H})$, red colour indicates oxygen atom $(\mathrm{O})$, grey colour for carbon atom $(\mathrm{C})$ and blue corresponds to nitrogen atom $(\mathrm{N})$.)

(ii) LYS (12) $\mathrm{H}$ of type-I collagen is linked with $\mathrm{O}$ (5) of GA with the bond distance of 2.15632 .

(iii) LYS (12) $\mathrm{H}$ of type-I collagen is linked with $\mathrm{O}$ (4) of GA with the bond distance of 1.96433 .

(H- Hydrogen; LYS- Lysine amino acid; O- Oxygen; GA- Glutaric acid)

With reference to the biocompatibility of the resulting polymers, cell attachment, proliferation assays were carried out. MTT assay was done to check the toxicity of the prepared biopolymers $(\mathrm{GACCH}$,
GACC, GADCCH and GADCC). Only cells that are metabolically normal can turn the tetrazolium salts into purple crystals. Compared with the native chitosan and type-I collagen, GACCH and GACC showed no significant differences in absorbance (figure 6), that is the biopolymers being in direct contact with fibroblast did not lead to apoptosis or necrosis. MTT results clearly indicated that NIH 3T3 cells proliferated well on the surface of the GA cross-linked biopolymers (GACCH and GACC). But less than $10 \%$ cell viability was observed for GADCCH and GADCC biopolymer, 


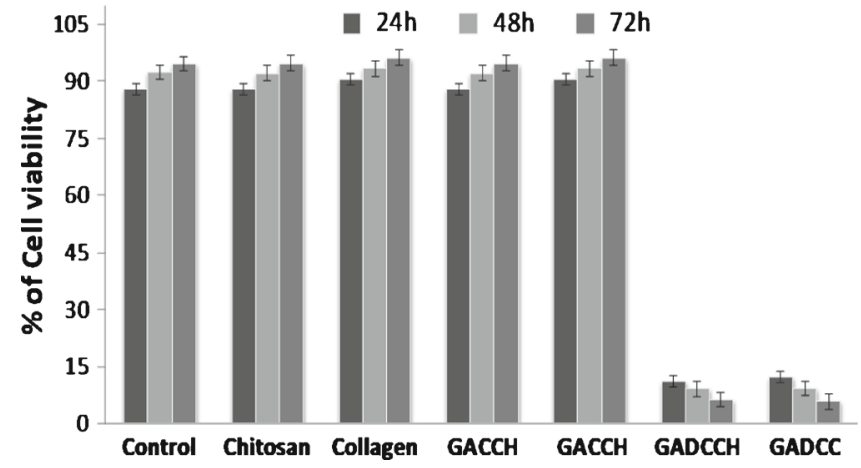

Figure 6. MTT analysis of control, chitosan, collagen, glutaric acid cross-linked chitosan $(\mathrm{GACCH})$, glutaric acid cross-linked collagen (GACC), glutaraldehyde cross-linked chitosan (GADCCH) and glutaraldehyde cross-linked collagen (GADCC) biopolymers at 24, 48 and $72 \mathrm{~h}$ time interval.

could be due to the toxic nature of GAD. Though glutaraldehyde (GAD) has been widely used as chemical cross-linking agent ${ }^{39}$ because of stabilizing the collagen efficiently, and the cross-linking is thought to involve the formation of Schiff bases, ${ }^{40}$ however, GAD-crosslinked biomaterials are poorly biocompatible with some cell lines including human fibroblasts, osteoblasts, chang cells, and endothelial cells. ${ }^{41-43}$ The side effects of GAD treatment were attributed to the degradation of the GAD-derived cross-links and the continuous release of aldehydes contributing to prolonged toxic effects. ${ }^{39,44}$

In cell viability assay we observed intense fluorescence of the cells on the surface of the native and crosslinked biopolymers and suggests the viability of the cells as illustrated in figure 7.

The SEM images of the cell seeded GACCH and GACC scaffold displayed in (figure $8 \mathrm{a}$ and $\mathrm{b}$ ) demonstrated that after being cultured for prolonged time (12 days), fibroblasts were detected in the scaffolds (GACCH and GACC) with typical spindle-shaped morphology and suggests that the cells were infiltrated into the scaffolds and further proliferated.
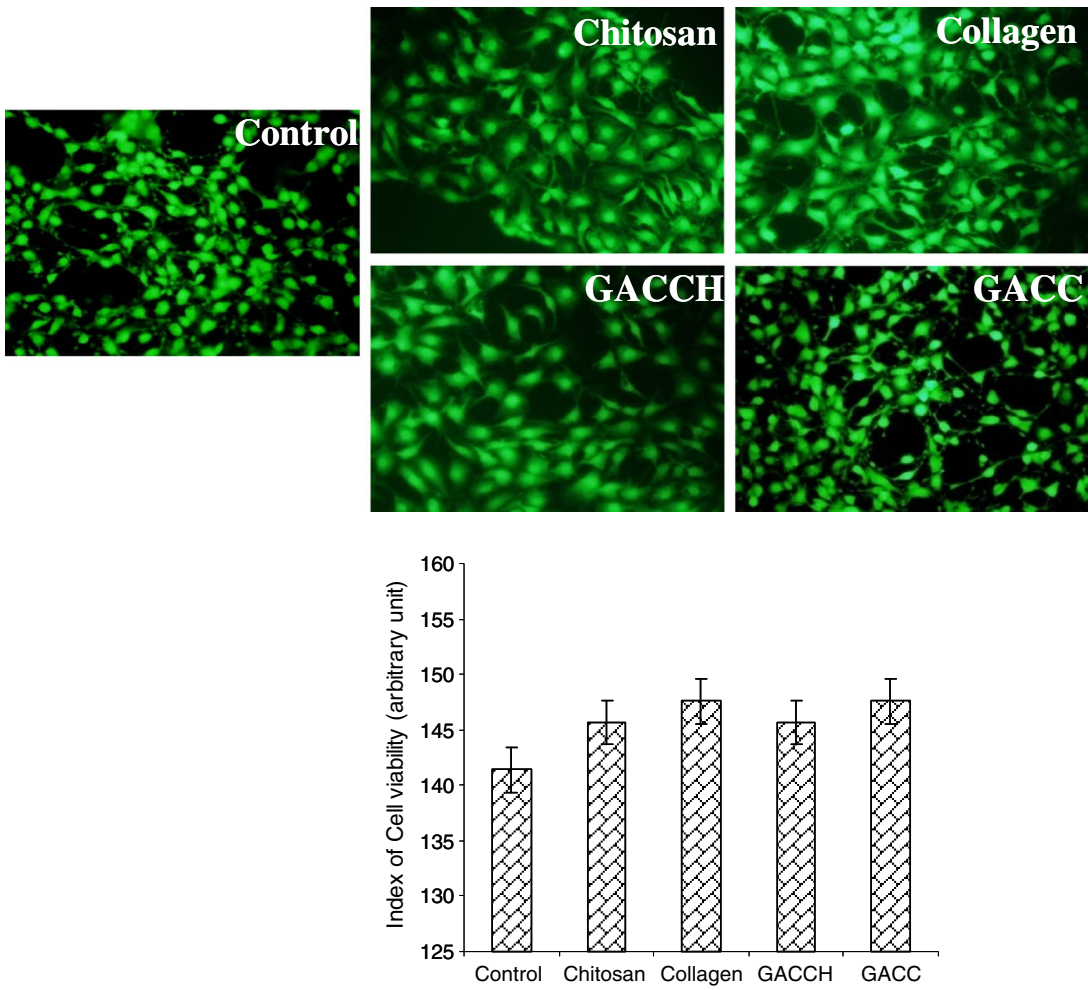

Figure 7. Index of cell viability (arbitrary unit) assessed in GACCH (glutaric acid cross-linked chitosan) and GACC (glutaric acid cross-linked collagen) in comparison with the parent molecules (chitosan and collagen) and control. (The assay was carried out using cell tracker kit. NIH3T3 Cells were treated on the surface of native and cross-linked biopolymers for $6 \mathrm{~h}$ followed by incubation with cell viable dye cell tracker for $30 \mathrm{~min}$. Fluorescence images of the cells were acquired by DP71 camera adapted to an Olympus IX71 microscope. Intensity of green positive cells were counted and plotted. Next, fluorescence intensities of the images were calculated using Adobe Photoshop version 7.0). 


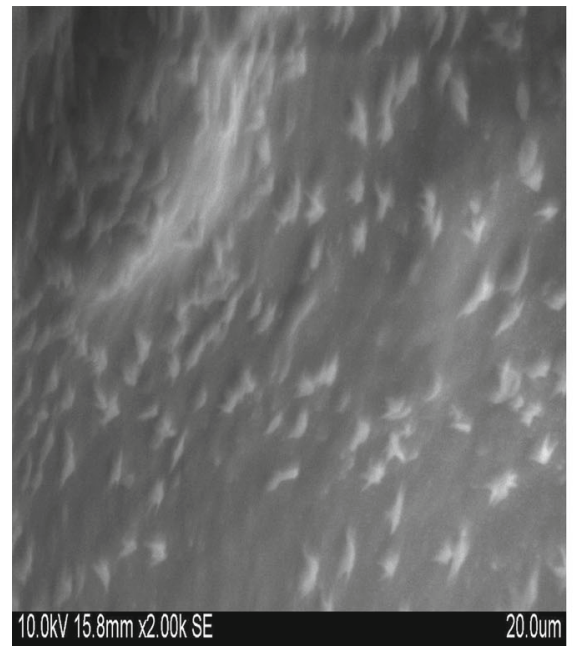

(a)

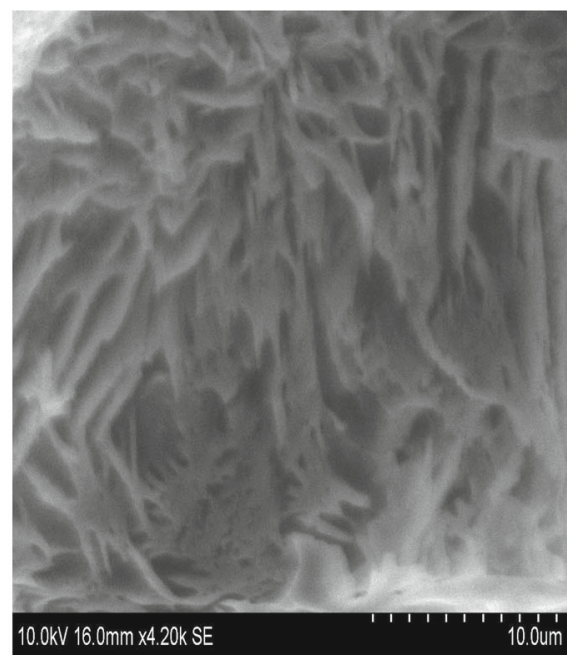

(b)

Figure 8. (a) Attachment of fibroblast cells on the GACCH (glutaric acid crosslinked chitosan) scaffold biopolymer. (b) Attachment of fibroblast cells on the GACC (glutaric acid cross-linked collagen) scaffold biopolymer. (Porous GACC scaffold was completely covered by fibroblast cells.)

\section{Conclusions}

The present study explicitly demonstrated that glutaric acid acts as suitable cross-linker for the preparation of biocompatible biopolymers from natural polymers (chitosan and collagen) with appreciable mechanical properties. The interaction between glutaric acid and chitosan or glutaric acid and collagen was identified as non-covalent interactions, i.e., both ionic and multiple intermolecular hydrogen bonding interactions. These non-covalent interactions provided the resulting biopolymers with high mechanical strength. All the instrumental analysis and bioinformatics tool authenticated the non-covalent interactions. The biopolymer material (scaffold) prepared upon cross-linking of glutaric acid with chitosan and or collagen was a green method. No toxic compounds were involved in this preparation and the resultant material is useful for applications as wound dressing material or as implant in clinical applications.

\section{Supplementary information}

Figure $\mathrm{S} 1$ as supplementary information can be seen in www.ias.ac.in/chemsci website.

\section{References}

1. Storck M, Orend K H and Schmitz-Rixen T 1993 Vasc. Endovasc. Surg. 27413
2. Hashimoto K, Sudo M, Sugimura T and Inagaki Y 2004 J. Appl. Polym. Sci. 923492

3. Liu Y, Guo L K, Huang L and Deng X M 2003 J. Appl. Polym. Sci. 903150

4. Engelmayr G C, Hildebrand D K, Sutherland F W H, Mayerand J E and Sacks M S 2003 Biomaterials 24 2523

5. Bourke S L and Kohn J 2003 Adv Drug. Deliv. Rev. 55 447

6. Ko H F, Feir C S and Kumta P N 2010 Philos. Trans. $R$ Soc. A 3681981

7. Cooper A, Bhattarai N and Zhang M 2011 Carb. Polym. 85149

8. Yan S, Zhang K, Liu Z, Zhang X, Gan L, Cao B, Chen X, Cui L and Yin J 2013 J. Mat. Chem. B. 11541

9. Krishnamoorthy G, Sehgal P K, Mandal A B and Sadulla S 2013 J. Biomat. Sci. Polym. Ed. 241

10. Li C, Wang L, Yang Z, Kim G, Chen H and Ge Z 2012 J. Biomat. Sci. Polym. Ed. 23405

11. Ballantyne B and Jordan S L 2001 J. Appl. Toxicol. 21 131

12. Leung H W 2001 Ecotoxicol. Environ. Saf. 4926

13. Beauchamp R O, St Clair M B, Fennell T R, Clarke D O and Morgan K T 1992 Crit. Rev. Toxicol. 22143

14. Kamiya K T, Kamiya H, Kaji H and Kasai H 1997 Mutat. Res. 377255

15. Tual C, Espuche E, Escoubes M and Domard A J 2000 J. Polym. Sci., Part B: Polym. Phys. 381521

16. Sheu M T, Huang J C, Yeh G C and Ho H O 2001 Biomaterials 221713

17. Schiffman J D and Schauer C L 2007 Biomacromolecules 8594

18. Mi F L, Tan Y C, Liang H C, Huang and Sung H W 2001 J. Biomater. Sci. Polym. Ed. 12835

19. Horn H J, Holland E G and Hazleton L W 1957 J. Agric. Food. Chem. 5759 
20. Mitra T, Sailakshmi G, Gnanamani A, Raja S T K, Thiruselvi T, Gowri V M, Selvaraj N V, Ramesh G and Mandal A B 2011 Int. J. Biol. Macromol. 48276

21. Bubnis W A and Ofner C M 1992 Anal. Biochem. 207 129

22. ChemSketch A C D 2009 Version 12 (Toronto, ON, Canada: Advanced Chemistry Development Inc.)

23. Madhan B, Subramanian V, Raghava Rao J, Nair B U and Ramasami T 2005 Int. J. Biol. Macromol. 3747

24. http://www.cgl.ucsf.edu./cgi-bin/gencollagen.py

25. Morris G M, Huey R, Lindstrom W, Sanner M F, Belew R K, Goodsell D S and Olson A J 2009 J Comput. Chem. 302785

26. Trentani L, Pelillo F, Pavesi F C, Ceciliani L, Cetta G and Forlino A 2002 Biomaterials 232863

27. Mossmann T 1983 Immunol. Methods 6555

28. Majumder S, Siamwala J H, Srinivasan S, Sinha S, Sridharan S R C, Soundararajan G, Seerapu H P and Chatterjee S 2011 J. Cell. Biochem 1121898

29. Kim S E, Cho Y W, Kang E J, Kwon I C, Lee E B, Kim J H, Chung H and Jeong S Y 2001 Fiber Polym. 264

30. Ohkawa K, Cha D I, Kim H, Nishida A and Yamamoto H 2004 Macromol. Rapid Commun. 251600

31. El-Tahlawy K, Gaffar M A and El-Rafie S 2006 Carbohydr. Polym. 63385

32. Bhumkar D R and Pokharkar V B 2006 AAPS Pharm. Sci. Technol. 71
33. Li Q X, Song B Z, Yang Z Q and Fan H L 2006 Carbohydr. Polym. 63272

34. Milosavljevic N B, Kljajevic L M, Popovic I G, Filipovic J M and Krusic M T K 2010 Polym. Inter. 59686

35. Vijayaraghavan R, Thompson B C, MacFarlane D R, Ramadhar K, Surianarayanan M, Aishwarya S and Sehgal P K 2010 Chem. Commun. 46294

36. Chen P H, Hwang Y H, Kuo T Y, Liu F H, Lai J Y and Hsieh H J 2007 J. Med. \& Biol. Eng. 2723

37. Pavia D L, Lampman G M and Kriz G S 2001 Introduction to spectroscopy, Third edition (USA: Thomson Learning Inc.)

38. Wang Y, Ameer G A, Sheppard B J and Langer R 2002 Nat. Biotech. 20602

39. Jorge-Herrero E, Fernandez P, Turnay J, Olmo N, Calero P, Garcia R, Freile L and Castillo-Olivares J J 1999 Biomaterials 20539

40. Olde Damink L H H, Dijkstra M, Van Luyn M J A, Van Wachem P B, Nieuwenhuis P and Feijen J 1995 J. Mater. Sci. Mater. Med. 6460

41. Huang-Lee L L H, Cheung D T and Nimni M J 1990 J. Biomed. Mat. Res. 241185

42. Van Luyn M J A, Van Wachen P B, Olde Damink L H H, Dijkstra P J, Feijen J and Nieuwenhuis P 1992 Biomaterials 131017

43. Gough J E, Scotchford C A and Downes S 2002 J. Biomed. Mat. Res. 61121

44. Schmidt C E and Baier J M 2000 Biomaterials 212215 